\title{
Analysis of the disturbance voltage and gpr in substation and mobile base station co-construction
}

\author{
Jie Long ${ }^{1}$, Shu-Yan Jia ${ }^{1}$, Shou-Ren Diao ${ }^{2}$ and Lu Wang ${ }^{3}$ \\ ${ }^{1}$ Jiaozuo Power Supply Company, State Grid Henan Electric Power Company, Jiaozuo, China \\ ${ }^{2}$ Information Communications Branch, State Grid Hebei Electric Power Company, Shijiazhuang, China \\ ${ }^{3}$ North China Electric Power University, Baoding, China
}

\begin{abstract}
It is essential to consider the electrical safety protection distance when the mobile base station and the substation are building together. This paper makes an analysis from three aspects: the influence on the disturbance voltage of the secondary cable in substation when the station is struck by lightning; the influence on the base station grounding grid caused by the station switching operation and short circuit faults. According to the relevant national and international standards, the electrical parameters are calculated when the substation and mobile base station grounding grid connected in different ways and different distance. The conclusion of the paper provides a theoretical basis for engineering construction with much higher practical value. Meanwhile, it is of great significance to develop the win-win co-operation between the power and telecommunications operators and to explore the diversified businesses of electric power.
\end{abstract}

\section{Introduction}

In recent years, with the communications users growing, the construction of mobile base station increased year by year. For independent mobile base stations which need to supply power to some large base stations, the costs associated are growing. The co-construction of mobile base station and substation may solve the problem of independent transformers, and to provide the thought of deep cooperation for the electric power department and telecommunication. According to the current study, the effects of lightning current to the base station were studied when mobile base stations struck by the lightning [1-2], the transient response of lightning strike to the substation ground network were researched in the literature[3-5], and the electromagnetic interference of switch operation of substation to secondary cable and the substation short-circuit fault were also studied [6-8]. Meanwhile, the related issue of the co-construction has not been clearly researched at home and abroad. In this paper, disturbance voltage and GPR are analyzed in substation and mobile base station co-construction. The calculation results provide theoretical basis for the construction of mobile base stations and substations.

\section{Model analysis}

In this article, calculation models of the substation grounding grid, mobile base station grounding grid, base station tower and secondary cable shielding layer are established through CDEGS (Current Distribution,
Electromagnetic Interference, Grounding and Soil Structure Analysis). The disturbance voltage and GPR are analyzed from three aspects. Firstly the substation and mobile base station grounding grid are connected in different ways and different distance. Then it is occurred that base station tower top is struck by lightning. Finally substation switch is operated and short circuit fault is appeared.

In this paper, practical operating $110 \mathrm{kV}$ substation and mobile base station in a certain area of Hebei served as the analysis background. Among that, the specification of the substation grounding grid is $72 \times 64.2 \mathrm{~m} 2$. The buried depth of horizontal ground rod is $0.8 \mathrm{~m}$. Vertical grounding depth is $1.5 \mathrm{~m}$. The flat steel of $50 \times 6 \mathrm{~mm} 2$ and steel angle of $50 \times 5 \times 2500 \mathrm{~mm} 3$ are used as level ground conductor and vertical grounding conductor separately. The vertical grounding system spacing of equalizing bring is $6 \mathrm{~m}$. The resistivity and permeability of the grounding conductor are $1.75 \times 10-8 \Omega \mathrm{m}$ and $4 \pi \times 10-7 \mathrm{H} / \mathrm{m}$. Soil resistivity of single layer used is $100 \Omega \mathrm{m}$. $\mathrm{KYJCE} / \mathrm{B} 3-14 \times 1.5$ is adopted as the $40 \mathrm{~m}$ target cable on both ends. Connected and unconnected model of substation and mobile base station grounding grid is shown in Figure 1

The mobile base station grounding grid is $3 \times 3 \mathrm{~m} 2$. Galvanized steel is used in ground network, grounding electrodes with $50 \times 50 \times 5 \mathrm{~mm} 3$ steel angle and the connection and introduction using $40 \times 4 \mathrm{~mm} 2$ flat steel. The high of base station tower reaches $45 \mathrm{~m}$. The base station tower model is shown in Figure 2. 


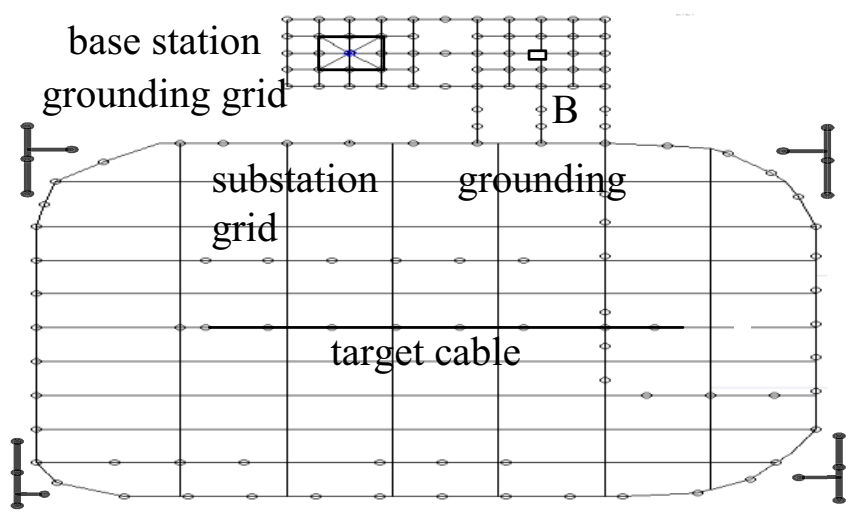

(a)

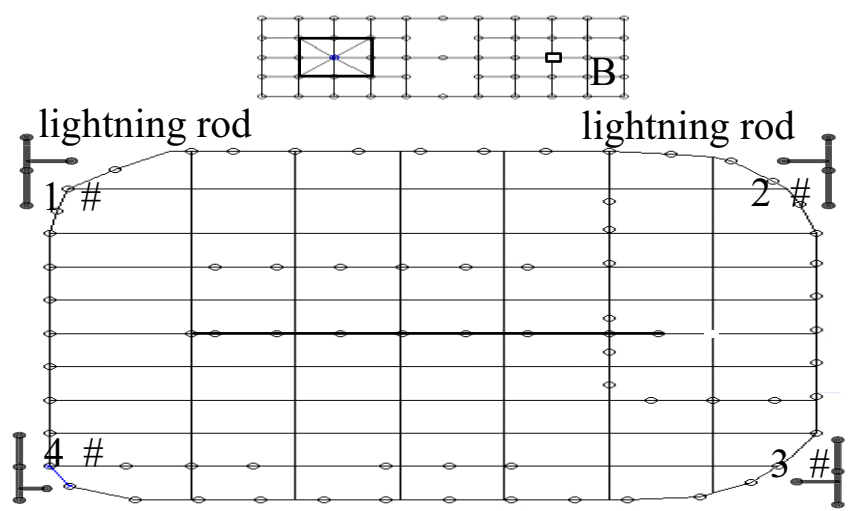

(b)

Figure 1. Grid model of substation and mobile base station:(a)Connected model,(b)Unconnected model.

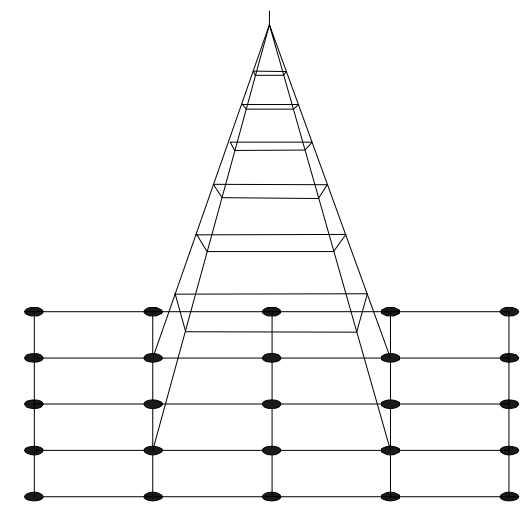

Figure 2. Station tower model

From the existing literature and experiments, lightning current amplitude in hebei region is mainly concentrated under 100kA. According to the most serious situation, 10/350s, 250kA double exponential lightning current model for the international standard IEC 623051in [9] is adopted. Lightning current expression is as follows:

$$
I(t)=I\left(e^{-\alpha t}-e^{-\beta t}\right)
$$

Among that, $\mathrm{I}=256107.3, \mathrm{a}=2049.38, \mathrm{~b}=563758.3$.

Transfer impedance expressions of secondary cable $[10]$ is as follows:

$$
Z_{\mathrm{T}}=Z_{d}+\mathrm{j} \omega\left(M_{h} \pm M_{b}\right)
$$

For that, computational formulas of Scattering impedance $\mathrm{Zd}$,Small inductance $\mathrm{Mh}$, Weave the inductance $\mathrm{Mb}$ are as follows:

$$
\begin{gathered}
Z_{d} \approx \frac{4}{\pi d^{2} \sigma n C \cos \alpha} \frac{(1+j) d / \delta}{\sin h((1+j) d / \delta)} \\
M_{h}=\frac{2 \mu_{0} C}{\pi \cos \alpha}\left(\frac{b}{\pi D_{\mathrm{m}}}\right)^{2} \exp \left(-\frac{\pi d}{b}-2\right) \\
M_{b}= \pm \frac{\mu_{0}\left[n d h+\left(b-\frac{b h}{d}\right) \frac{(h+b)}{2}+B\right] A}{2 \pi C\left(D_{0}+2 d+h\right) \cos \alpha}
\end{gathered}
$$

Of which: $\mathrm{b}=4 \pi \cos / \mathrm{C}-\mathrm{nd}, \quad \mathrm{h}=2 \mathrm{bd} /(\mathrm{b}+\mathrm{d}), \quad \mathrm{B}=\mathrm{n}(\mathrm{d} 2-$ $\pi \mathrm{d} 2 / 4), \mathrm{A}=(\sqrt{v}+1) 2 \cos (2 \alpha), v=\mathrm{C} 2 \sin \alpha /(4 \pi \mathrm{acos} \alpha)$.

The diameter of the insulation layer is $\mathrm{D} 0=3.1 \mathrm{~mm}$. The diameter of each braided line is $\mathrm{d}=0.2 \mathrm{~mm}$. The number of weaving beam braid is $\mathrm{C}=24$. The number of wires in weaving beam is $n=6$. The average radius of woven layer is $\mathrm{a}=7.8 \mathrm{~mm}$, the braided angle $\alpha=38.1^{\circ}$ 。

\section{Calculation method and process}

\subsection{Lightning}

In order to reduce the lightning current to zero, the duration of the lightning current is $\mathrm{T}=2500 \mathrm{~s}$. The sampling index is $n=15$. The sampling time interval is $\mathrm{t}=0.0763 \mathrm{~s}$. The Nyquist frequency is $\mathrm{f}=6.554 \mathrm{MHz}$. Because the lightning current waveform rise is very steep, it leads to a wide spectrum of lightning current. However, the main frequency components are less than $50 \mathrm{kHz}$. Therefore, it selects 422 frequency points, which are mainly low frequency components and a small amount of high frequency components to get the main frequency of lightning current. The lightning current waveform is shown in figure 3 . The main calculation process is three steps. Firstly, the spectral density of the lightning current is calculated with the FFT. Based on the characteristics of its spectral density, the right amount of calculating frequency points is selected. Second, it is necessary to calculate the unit current of the cable shielding layer through the CDEGS, when the excitation source is given frequency points and the corresponding unit injection current. The unit current of the cable shielding layer and the amplitude spectrum of the corresponding lightning current are multiplied to obtain the total current of shielding layer. At last, it is obtained the disturbance voltage that the total current of shielding layer and the transfer impedance of the shielded cable are multiplied. And the time domain waveform of the disturbance voltage is calculated with IFFT.

\subsection{Switching operation}

This paper mainly studies the influence of switching operation in substation on the second equipment of mobile base station. The transient overvoltage caused by the station switching operation causes the uneven ground potential rise of the substation grounding grid and the base station grounding grid. The specific calculation process is similar to that of the lightning. 
This paper analyzes the over voltage with the double exponential function[11]. The specific expression is as follows:

$$
u(t)=A U_{\mathrm{p}}\left(e^{t / \tau_{1}}-e^{t / \tau_{2}}\right)
$$

Where, Up for peak value, A for wave coefficient, $\tau 1$, $\tau 2$ for time constant, the front time/half peak time: $250 / 2500, \tau 1=-0.315, \tau 2=-62.500, \quad \mathrm{~A}=1.104, \quad \mathrm{Up}$ is normalized

\subsection{Short circuit fault}

The most serious harm is the fault current in the ground when the short-circuit failure occurs in the substation, rather than the total short-circuit current. The calculation of fault current in the ground needs to consider the shunt coefficient of the ground grid. The expression of the shunt coefficient of the grounding grid is Ksg. That is:

$$
K_{\mathrm{sg}}=\frac{I_{\mathrm{g}}}{I_{0}-I_{\mathrm{N}}}
$$

Where I0 is the short-circuit current provided by the power supply. IN is the current flowing through the neutral point of the transformer or the generator. Iw is the total current flowing through the ground wire.

According to the actual data of the actual substation, the maximum short-circuit current is $11 \mathrm{kA}$. And the shunt coefficient of the grounding grid is $\mathrm{Ksg}=0.5$. So the fault current is $\mathrm{Ig}=5.5 \mathrm{kA}$. The specific calculation process is similar to that of the lightning.

\section{Computation results}

Through the model of CDEGS, this paper analyzes the connection and non-connection of substation grounding grid and mobile base station grounding grid. The article gives an analysis of the grounding grid spacing in five respects: $\mathrm{d} 1=10 \mathrm{~m} 、 \mathrm{~d} 2=20 \mathrm{~m} 、 \mathrm{~d} 3=30 \mathrm{~m} 、 \mathrm{~d} 4=40 \mathrm{~m}$ 、 $\mathrm{d} 5=50 \mathrm{~m}$. The calculation result of the disturbance voltage of the secondary cable in substation when the station is struck by lightning is shown in Figure 3. The GPR of point $\mathrm{B}$ caused by the station switching operation is shown in Figure 4. The power frequency transient voltage of point B with short circuit fault is shown in figure 5 .

Three conclusions can be obtained from the analysis of the results of the calculation. The disturbance voltage of the secondary cable and GPR are maximum with the grounding grid connection and minimum distance. (1) The maximum disturbance voltage is $0.2772 \mathrm{kV}$ when the top of the base station is struck by lightning. (2) The maximum GPR of point $B$ caused by the station switching operation is $0.5965 \mathrm{kV}$. The maximum power frequency transient voltage of point $\mathrm{B}$ with short circuit fault is $3.3583 \mathrm{kV}$.

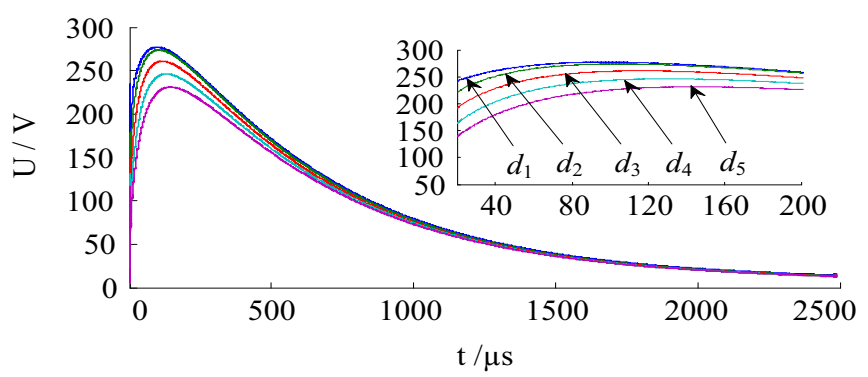

(a)

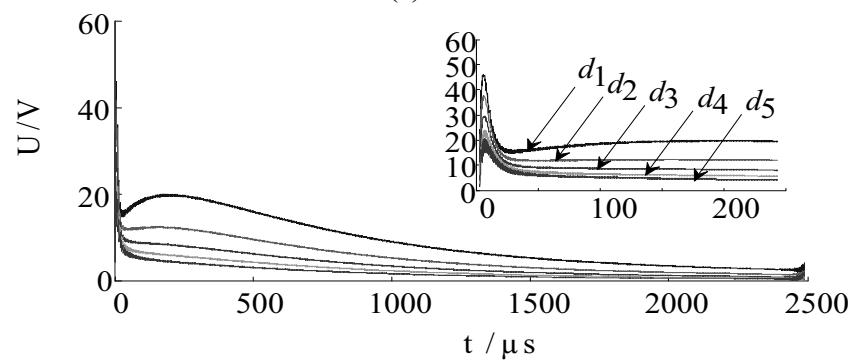

(b)

Figure 3. Disturbance voltage waveform of the cable shielding layer (different distance):(a)connection,(b)non-connection.

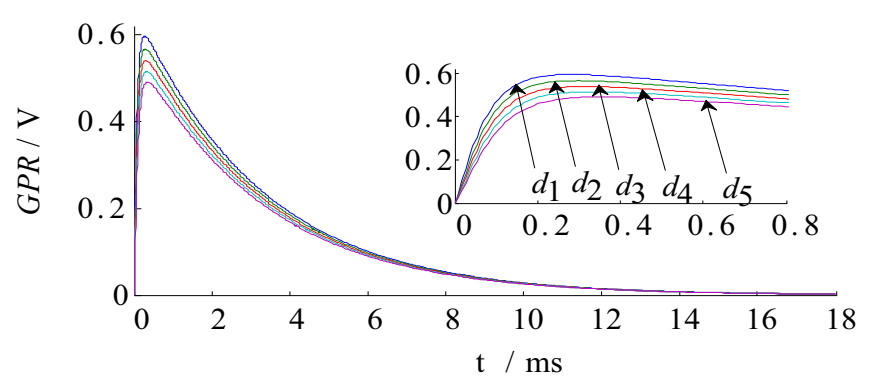

(a)

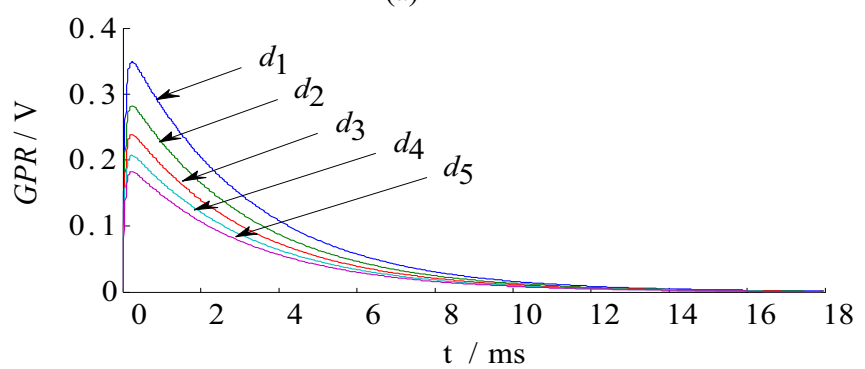

(b)

Figure 4. GPR of point B with switching overvoltage (different distance):(a)connection,(b)non-connection

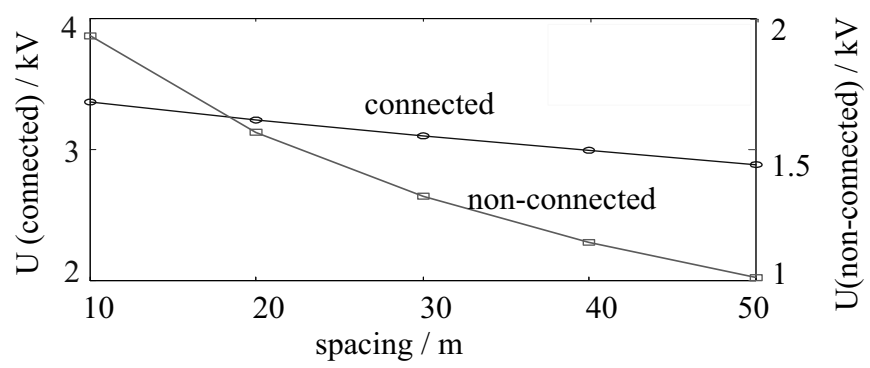

Figure 5. Power frequency transient voltage of point B with short circuit fault (different distance, connected, non-connected).

In this paper, the size of disturbance voltage of cable port with lightning striking the different lightning rod is calculated to verify the connection reliability of the 
grounding grid. The calculation results are shown in Table 1. Where, 1\#: lightning striking the 1st lightning rod; 2\#: lightning striking the 2 st lightning rod. 3\#: lightning striking the 3 st lightning rod. 4\#: lightning striking the 4st lightning rod. 5\#: lightning striking the 5st lightning rod (grounding grid connection). 6\#: lightning striking the 6st lightning rod (grounding grid nonconnection). As shown in Table 1, the disturbance voltage of the cable with the grounding grid connected or non-connected is less than that of the cable when the lightning strikes each lightning rod. The disturbance voltage of the cable is less than $0.4 \mathrm{kV}$ when the lightning amplitude is lower than $100 \mathrm{kV}$. Because the lightning current amplitude of Hebei area is mainly concentrated in $100 \mathrm{kA}$, the disturbance voltage can meet the national standards. The maximum disturbance voltage of the cable when lightning strikes the base station is $0.15 \mathrm{kV}$.

Table 1. Relationship between lightning amplitude and cable port disturbance voltage with different lightning point.

\begin{tabular}{|c|c|c|c|c|c|c|}
\hline \multirow{2}{*}{$\begin{array}{l}\text { Lightnin } \\
\text { gmplitud } \\
\text { e } \\
\text { /kA }\end{array}$} & \multicolumn{6}{|c|}{ Disturbance Voltage /kV } \\
\cline { 2 - 7 } & $1 \#$ & $2 \#$ & $3 \#$ & $4 \#$ & $5 \#$ & $6 \#$ \\
\hline 200 & 0.615 & 0.580 & 0.649 & 0.656 & 0.221 & 0.037 \\
\hline 150 & 0.461 & 0.435 & 0.487 & 0.492 & 0.166 & 0.027 \\
\hline 100 & 0.307 & 0.290 & 0.324 & 0.328 & 0.110 & 0.018 \\
\hline 80 & 0.246 & 0.232 & 0.259 & 0.262 & 0.088 & 0.014 \\
\hline 80 & 0.246 & 0.232 & 0.259 & 0.262 & 0.088 & 0.014 \\
\hline
\end{tabular}

It is essential to consider the interference degree of the equipment when the electrical safety protection distance is calculated. According to the existing standard [12], the limiting value of the target cable disturbance voltage is $\mathrm{U} 1=0.5 \mathrm{kV}$ when the station is struck by lightning. The limiting value of transient ground potential rise is $\mathrm{U} 2=50 \mathrm{kV}$ with the point $\mathrm{B}$ caused by the station switching operation. The limiting value of the power frequency transient voltage with short circuit fault is $\mathrm{U} 3=5 \mathrm{kV}$.

Because the electromagnetic disturbance voltage of the connected grounding grid is less than that of the nonconnected grounding grid, the protective distance of the non-connection mode is mainly analyzed. As shown in Table 2 the relationship between the cable safety length and different distance with grids non-connected is analyzed, when the lightning current amplitude is $250 \mathrm{kA}$. The relationship between the operating voltage and distance of grounding grid non-connected is calculated. According to the amplitude of different operation voltage waveform, the corresponding grounding grid spacing is selected as shown in Table 3. The relationship between different short circuit grounding current and distance of grounding grids non-connected is analyzed as shown in table 4. The corresponding grounding grid spacing is selected by using different short-circuit current.
Table 2. Relationship between the cable safety length and different distance with grids non-connected.

\begin{tabular}{|c|c|c|c|c|c|}
\hline \multirow{2}{*}{$\begin{array}{c}\text { Length } \\
/ \mathbf{m}\end{array}$} & \multicolumn{5}{|c|}{$\mathbf{U 1 / k V}$} \\
\cline { 2 - 6 } & $\mathrm{d} 1$ & $\mathrm{~d} 2$ & $\mathrm{~d} 3$ & $\mathrm{~d} 4$ & $\mathrm{~d} 5$ \\
\hline 200 & 0.6156 & 0.5801 & 0.6497 & 0.6569 & 0.2218 \\
\hline 150 & 0.4617 & 0.4351 & 0.4872 & 0.4927 & 0.1663 \\
\hline 100 & 0.3078 & 0.2901 & 0.3248 & 0.3285 & 0.1109 \\
\hline 80 & 0.2462 & 0.2320 & 0.2599 & 0.2628 & 0.0887 \\
\hline
\end{tabular}

Table 3. Relationship between the operating voltage and distance of grounding grid non-connected.

\begin{tabular}{|c|c|c|c|c|c|}
\hline \multirow{2}{*}{$\begin{array}{c}\text { Length } \\
\text { /m }\end{array}$} & \multicolumn{5}{|c|}{ U1/kV } \\
\cline { 2 - 6 } & $\mathrm{d} 1$ & $\mathrm{~d} 2$ & $\mathrm{~d} 3$ & $\mathrm{~d} 4$ & $\mathrm{~d} 5$ \\
\hline 140 & 47.423 & ---- & ---- & ---- & ---- \\
\hline 150 & 50.585 & ---- & ---- & ---- & ---- \\
\hline 170 & ---- & 48.628 & ---- & ---- & ---- \\
\hline 180 & ---- & 51.187 & ---- & ---- & ---- \\
\hline 210 & ---- & ---- & 49.731 & ---- & ---- \\
\hline 220 & ---- & ---- & 51.893 & ---- & ---- \\
\hline 240 & ---- & ---- & ---- & 48.746 & ---- \\
\hline 250 & ---- & ---- & ---- & 50.621 & ---- \\
\hline 270 & ---- & ---- & ---- & ---- & 49.681 \\
\hline 280 & ---- & ---- & ---- & ---- & 51.337 \\
\hline
\end{tabular}

Table 4. Relationship between different short circuit grounding current and distance of grounding grids non-connected.

\begin{tabular}{|c|c|c|c|c|c|}
\hline \multirow{2}{*}{$\begin{array}{c}\text { Length } \\
\text { /m }\end{array}$} & \multicolumn{5}{|c|}{ U1/kV } \\
\cline { 2 - 6 } & $\mathrm{d} 1$ & $\mathrm{~d} 2$ & $\mathrm{~d} 3$ & $\mathrm{~d} 4$ & $\mathrm{~d} 5$ \\
\hline 14 & 4.922 & ---- & ---- & ---- & ---- \\
\hline 15 & 5.274 & ---- & ---- & ---- & ---- \\
\hline 17 & ---- & 4.833 & ---- & ---- & ---- \\
\hline 18 & ---- & 6.329 & ---- & ---- & ---- \\
\hline 20 & ---- & ---- & 4.802 & ---- & ---- \\
\hline 21 & ---- & ---- & 5.042 & ---- & ---- \\
\hline 24 & ---- & ---- & ---- & 4.994 & ---- \\
\hline 25 & ---- & ---- & ---- & 5.203 & ---- \\
\hline 27 & ---- & ---- & --- & ---- & 4.9605 \\
\hline 28 & ---- & --- & --- & ---- & 5.1441 \\
\hline
\end{tabular}


Through the analysis of the above, the longer the length of the cable safety, the greater the magnitude of the operating voltage, the greater the limitation of the short circuit current can be allowed with the greater the distance between the grounding grid.

\section{Conclusions}

This paper makes an analysis about the problem of electrical protection spacing when the mobile base station and the substation are built together. It establishes the calculation model of substation grounding grid, mobile base station grounding grid, base station tower and the secondary cable. The minimum disturbance voltage, minimum ground potential rise and power frequency transient voltage can be obtained by calculation with grounding grid non- connected and the largest spacing.

The program of 10 meters and non-connected grounding grid spacing can be used when the mobile base stations and substations are building together. The conclusion of the paper provides a theoretical basis for engineering construction with much higher practical value. Meanwhile, it is of great significance to develop the win-win co-operation between the power and telecommunications operators and to explore the diversified businesses of electric power.

\section{References}

1. P. Farid, B. Dawalibi, W. Ruan, S. Fortin, Proceedings of Internat-ional Conference on Electromagnetic Compatibility, (1995)

2. P. Li, Y.-H. Lv, Z.-W. Li, Chinese Journal of Radio Science 101, 66 (2012)

3. L.-L. Li, Z.-Y. Xie, N. Li, Electrical Measurement \& Instrumentation 2, 37 (2008)

4. M.-L. Wu, X. Cui, High Voltage Engineering 6, 1 (2003)

5. W. Ruan, S. Fortin, F. P. Dawalibi, Asia-Pacific International Conference, (2011)

6. C.-H. Zhang, Y. Wang, X.-M. Xie, Electrical Measurement \&Instrumentation 10, 94 (2013)

7. G. Yu, J.-L. He, B.-C. Mao, Electro technical Journal 12, 19 (2002)

8. B. Zhang, J.-P. Wu, H. Xiao, High Voltage Engineering, 3, 720 (2012)

9. IEC, IEC 62305-1 Protection against lightning-Part 1: General principles, ( Geneva: IEC, 2006)

10. H. Ma, J.-P. Ge, K. Wu, Wire and cable 6, 1 (1993)

11. GB/T 17626-1 Electromagnetic compatibilityTesting and measurement techniques, (China Standard Press, 2006)

12. GB/T 17626-1 Electromagnetic compatibilityTesting andmeasurement techniques, (China Standard Press, 2006) 